\title{
Diversity of the adapisoriculid mammals from the early Palaeocene of Hainin, Belgium
}

Eric De Bast, Bernard Sigé, and Thierry Smith

Acta Palaeontologica Polonica 57 (1), 2012: 35-52 doi: http://dx.doi.org/10.4202/app.2010.0115

Adapisoriculidae are an enigmatic group of small mammals known from the late Cretaceous of India, and from the early Palaeocene to early Eocene of Europe and Africa. Based on their primitive dental morphology, they have been classified as didelphids, nyctitheriids, leptictids, mixodectids, tupaiids, and palaeoryctids. While the latest hypothesis based on dental morphology suggests an affinity with Lipotyphla, postcranial remains indicate a close relationship with Euarchonta. Here, we present new adapisoriculid dental remains from the early Palaeocene locality of Hainin (Belgium). Adapisoriculidae are particularly abundant in Hainin, where they represent about one third of the mammalian fauna, offering new insights into both their specific and generic phylogenetic interrelationships. We describe three new species (Afrodon gheerbranti sp. nov., Bustylus folieae sp. nov. and Proremiculus lagnauxi gen. et sp. nov.) and document the previously unknown lower dentition of Bustylus marandati. The diversity of dental morphologies observed in the Hainin fauna suggests different interrelationships than previously suggested. In particular, the genus Proremiculus is considered morphologically intermediate between Afrodon and Remiculus, and the latter is no longer recognised as the sister group of Adapisoriculus. Although the highest diversity of adapisoriculids occurs in Europe, the oldest and most primitive members of the family were found in India and Africa, respectively. The geographic origin of the family could thus be located in any of these three continents, depending on the importance attributed to each of these factors. The coexistence of primitive and derived adapisoriculids at Hainin might indicate a very quick diversification in Europe, probably starting around the K-T boundary.

Key words: Mammalia, Adapisoriculidae, phylogeny, early Palaeocene, Hainin, Belgium.

Eric De Bast [eric.debast@naturalsciences.be] and Thierry Smith [thierry.smith@naturalsciences.be ], Royal Belgian Institute of Natural Sciences, Department of Paleontology, Rue Vautier 29, B-1000 Brussels, Belgium; Bernard Sigé [bernard-sige@ orange.fr], Laboratoire de Paléontologie, Institut des Sciences de l'Evolution, cc064, Université Montpellier II, place Eugène Bataillon, 34095 Montpellier cedex 05, France. 
This is an open-access article distributed under the terms of the Creative Commons

Attribution License (for details please see creativecommons.org), which permits unrestricted use, distribution, and reproduction in any medium, provided the original author and source are credited.

FoF 